\title{
MRS/CMR Apprentice Science Reporters Program Advances Materials Careers
}

"Science exists because scientists are writers and speakers.... Research that never sees the dark of print remains either hidden or virtual or nonexistent. Publication and public speaking are how scientific work gains a presence, a shared reality in the world," said Scott L. Montgomery in his book The Chicago Guide to Communicating Science (The University of Chicago Press, 2002). It was in this spirit that the Apprentice Science Reporters program was conceived.

The Apprentice Science Reporters program is a unique collaboration between the Materials Research Society and the National Science Foundation (NSF)sponsored International Center for Materials Research (ICMR) (www.icmr. ucsb.edu) at the University of California, Santa Barbara. The program builds on MRS's on-going coverage of materialsrelated conferences through the Meeting Scenes (www.mrs.org/meetingscene); these are daily e-mail reports sent by MRS reporters directly from conference venues to around 38,000 materials professionals worldwide. In 2008 we began sending materials science and engineering graduate students and postdoctoral researchers to international MRS meetings as trainee science writers and journalists. These Apprentice Science Reporters attended talks (including many outside of their own research specialty) and worked with the MRS reporters to compile technical summaries for the Meeting Scene daily e-mails. They also contributed to the MRS Meetings blog, http:/ / materials.typepad.com. These activities provided valuable science writing training and exposure to diverse fields of materials research in an international context.

In 2008, a total of four students and one postdoctoral fellow participated in the program, attending and reporting on five conferences in Strasbourg (France), Chongqing (China), Sydney (Australia), Cancún (Mexico), and Nagoya (Japan).

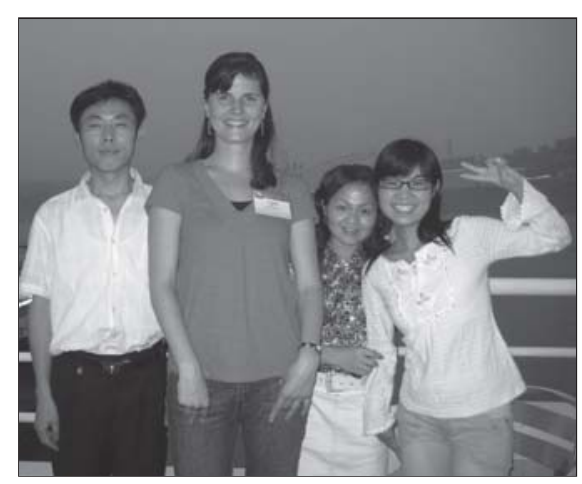

Through the Apprentice Science Reporters Program, graduate student Alison Hatt from the University of California, Santa Barbara (second from left) worked with graduate students in China at the International Materials Research Conference in Chongqing, China, held jointly by the Materials Research Society and the Chinese Materials Research Society.

Graduate student Arthur Feldman, from the University of Michigan, who attended the European MRS meeting in Strasbourg, France, in May 2008, said, "Spending a week as a reporter at the European Materials Research Society turned into a unique conference experience for me. I attended a broader range of symposia than I normally would, and synthesizing my conference notes into write ups allowed me to consider the connections between the different fields of materials research. Acting as a reporter resulted in my meeting and talking to more people while at the conference and I imagine will be quite helpful when looking for postdoctoral opportunities. I very much appreciate the opportunity granted by the ICMR to travel to far away conferences to enhance my skills as a communicator of science."
Graduate student Alison Hatt from the University of California, Santa Barbara, who worked with Chinese graduate students at the International Materials Research Conference in Chongqing, China (see photo), said, "During the apprenticeship I gained first-hand experience writing in a professional environment, receiving immediate feedback on my work and learning to perform under pressure. It let me explore science writing as a potential career path but also gave me useful insight into scientific communication in general. An additional benefit was the unique opportunity to engage with Chinese students and researchers, forging valuable connections and friendships."

One of the goals of the Materials Research Society is to encourage and nurture young materials researchers and to help further their careers. Communication of science and training of young scientists are also important goals of the NSF and the ICMR. The Apprentice Science Reporters program works toward all of these goals, through sending students and postdoctoral researchers to conferences outside of the United States, and helping them to communicate the science and their experiences to the wider community. The program is especially useful for young scientists considering a career in science writing and journalism, or in science communication in general.

Similar opportunities may be available in 2009 for graduate students to participate in the MRS/ICMR Apprentice Science Reporters program. For more information, contact Gopal Rao at rao@mrs.org or Nicola Spaldin at nicola@ mrl.ucsb.edu. Archives of the Meeting Scene are available on the MRS Web site, www.mrs.org/meetingscene.

GOPAL RAO

Materials Research Society

NiCOLA SPALDIN

University of California-Santa Barbara

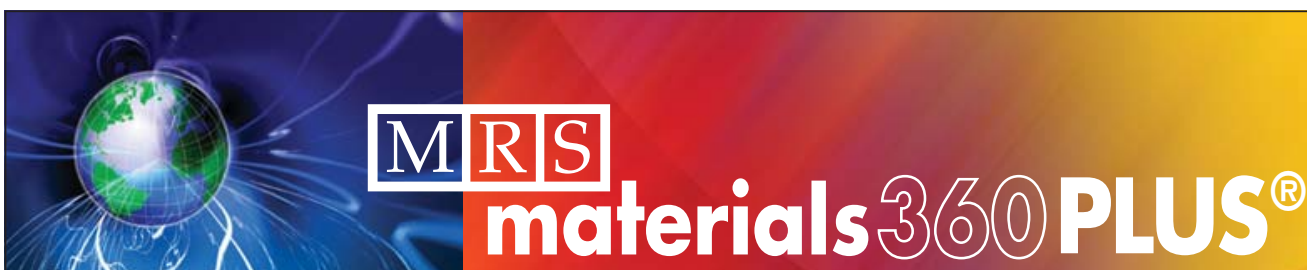

www.mrs.org/360plus
Materials News

Materials Information Resources and Links Meetings Calendar and Much More! 